\title{
Development of ANN Based Relay Algorithm for Protection of Series Compensated Transmission Line
}

\author{
Nikita Singh ${ }^{1}$, H.K. Verma ${ }^{2}$, Soma Deb ${ }^{3}$ \\ ${ }^{1}$ M-Tech Student, ${ }^{2}$ Distinguished Professor, ${ }^{3}$ Assistant Professor, Department of Electrical and Electronics \\ Engineering, School of Engineering and Technology, Sharda University, Greater Noida (U.P)-201306, India
}

\begin{abstract}
This paper presents a relaying algorithm based on Artificial Neural Network (ANN) technique for the detection and classification of faults on series compensated transmission lines. A $400 \mathrm{kV}, 100 \mathrm{~km}, 50 \mathrm{~Hz}$ transmission line was simulated in PSCAD/EMTDC for generating signals for the training and testing of the $A N N$. Ten types of fault were created at middle of the line and at the remote end. Four inception angles $\left(0^{\circ}, 90^{\circ}\right.$, $180^{\circ}$ and $270^{\circ}$ ) have been taken for the training and four different inception angles $\left(45^{\circ}, 135^{\circ}, 225^{\circ}\right.$ and $\left.315^{\circ}\right)$ for the testing. The ANN has six inputs, viz three line to line voltages $\left(V_{a b}, V_{b c}, V_{c a}\right)$ and three ratios of sequence currents $\left(I_{p} / I_{\text {Load }}, I_{D} / I_{P}\right.$ and $\left.I_{n} / I_{P}\right)$. It has eleven outputs: one output for no fault condition and the remaining ten for the various types of faults. ANN was trained and tested using back-propagation algorithm. The results show that the relay algorithm is capable of fault detection and classification, both with and without series capacitor and for fault occurring anywhere on the protected section of the line. Accuracy of 100\% has been achieved with ANN for a delay of $12 \mathrm{~ms}$.
\end{abstract}

Keywords: ANN, Back propogation algorithm, MATLAB, PSCAD/EMTDC, Series compensation, Transmission line.

\section{Introduction}

Protection of transmission line is an important aspect in the field of power system protection as occurrence of faults on transmission lines is quite often due to their long lengths and unfriendly topography of the area through which they pass. Use of series capacitors on power transmission lines provide the benefits of increased system stability, better voltage regulation and increase in power transfer capability. Value of the series capacitor is selected to compensate partly for the inductive reactance of the line.

Bogdan Kasztenny [1] and Clint T. Summers [2] analyzed the problems related to the distance protection of transmission lines equipped with series capacitors. Use of artificial intelligence techniques can take care of these problems [3]. One recent paper reports the use of artificial neural network (ANN) for uncompensated transmission line [4]. The authors use ANN with 6-neuron input layer, first hidden layer with 6 neurons, second hidden layer with 2 neurons and a single-neuron output layer. The accuracy achieved in fault detection was $78.82 \%$ and only one type of fault (namely, line ' $a$ ' to ground fault) was considered.

This paper reports the development of a relay algorithm for the protection of series compensated transmission line using ANN. The proposed algorithm not only detects but also classifies the fault and identifies the faulted phase on the transmission line. It works very well for both cases, namely with and without series capacitor. The ANN has six inputs: three line to line voltages $\left(\mathrm{V}_{\mathrm{ab}}, \mathrm{V}_{\mathrm{bc}}\right.$ and $\left.\mathrm{V}_{\mathrm{ca}}\right)$ and three ratio of sequence currents $\left(I_{p} / I_{L o a d}, I_{0} / I_{P}\right.$ and $\left.I_{n} / I_{P}\right)$. It has eleven outputs: one output is for no fault and the remaining ten are for various types of fault.

A $400 \mathrm{kV}, 100 \mathrm{~km}, 50 \mathrm{~Hz}$ transmission line with $200 \mu \mathrm{F}$ series capacitor was simulated using PSCAD/EMTDC The line is fed from one end. Voltage and current signals are generated at the relay point for uncompensated line as well as series compensated line under varying conditions of fault (fault inception angle, fault location and type of fault). For the protection of series capacitor, metal oxide varistor (MOV) is also inserted in the power transmission line, which bypasses the series capacitor on overvoltages [2].

\section{Series Compensated Transmission Line}

Transmission lines are the largest components of a power system which stretch out over large distances passing through various geographical and environmental backgrounds. Often a need arises to explore the various options for improving the power transfer capacity of the transmission line, which is given by

$$
\mathrm{P}=\frac{|V s||V r|}{\mathrm{XL}} \operatorname{Sin} \delta
$$

where, $V_{S}$ is the sending end voltage, $V_{R}$ is the receiving end voltage, $X_{L}$ is the transmission line reactance and $\delta$ is the power angle [5]. 
However, knowing the fact that $\mathrm{X}_{\mathrm{L}}$ is inductive in nature, a capacitor is installed in series with the transmission line in order to compensate the inductive voltage drop. With series capacitor inserted in the line, the expression for power transfer capacity becomes

$$
\mathrm{P}=\frac{|V s\|\mid V r\|}{\mathrm{XL}-\mathrm{Xc}} \operatorname{Sin} \delta
$$

where, $\mathrm{X}_{\mathrm{C}}$ is the reactance of the series capacitor.

\section{1: Location of series capacitor}

A series capacitor bank can theoretically be located anywhere along the line. Factors influencing choice of location include cost, accessibility, fault level, protective relaying considerations, voltage profile and effectiveness in improving power transfer capability [5]

The usual locations considered are the midpoint and remote end of the line. In the present study, the series capacitor is located at the mid-point of the line.

\section{2: Values of series capacitor}

For a three-phase line, the inductance per phase is given by [6]

Where,

$$
\mathrm{L}=2 \times 10^{-7} \ln (\mathrm{GMD} / \mathrm{GMR})
$$

GMD is the geometric mean distance and GMR is the geometric mean radius

Using the GMD and GMR data for the $400 \mathrm{kV}$ line simulated here, we get

$\mathrm{L}=12.19848 \times 10^{-7} \mathrm{H} / \mathrm{m}$

At $50 \mathrm{~Hz}$, the inductive reactance per phase is then

$\mathrm{X}_{\mathrm{L}}==0.2939 \times 10^{-3} \Omega / \mathrm{m}$

For $100 \mathrm{~km}$ line,

$$
\mathrm{X}_{\mathrm{L}}=29.39 \Omega
$$

A common practice is to select the value of series capacitor (C) for 50-70\% compensation of inductive reactance. In the present simulation, the value of $\mathrm{C}$ has been selected for $50 \%$ compensation. Accordingly

$$
\mathrm{X}_{\mathrm{C}}=14.69 \Omega
$$

At $50 \mathrm{~Hz}$,

$$
\mathrm{C}=218 \mu \mathrm{F}
$$

A rounded-off value of $200 \mu \mathrm{F}$ has been used in the simulation.

\section{Data Generation for Training and Testing Of Ann}

A $400 \mathrm{kV}, 100 \mathrm{~km}, 50 \mathrm{~Hz}$ transmission line was simulated in PSCAD/EMTDC as shown in figure 1. Ten types of fault were created on the line. The following nine signals were generated and recorded at the source end, which is the relay location:

1. RMS values of line-to-line voltages $\left(\mathrm{V}_{\mathrm{ab}}, \mathrm{V}_{\mathrm{bc}}, \mathrm{V}_{\mathrm{ca}}\right)$

2. RMS values of line currents $\left(\mathrm{I}_{\mathrm{a}}, \mathrm{I}_{\mathrm{b}}, \mathrm{I}_{\mathrm{c}}\right)$

3. Ratios of sequence components of currents $\left(\mathrm{I}_{\mathrm{n}} / \mathrm{I}_{\mathrm{p}}, \mathrm{I}_{0} / \mathrm{I}_{\mathrm{p}}, \mathrm{I}_{\mathrm{p}} / \mathrm{I}_{\mathrm{load}}\right)$

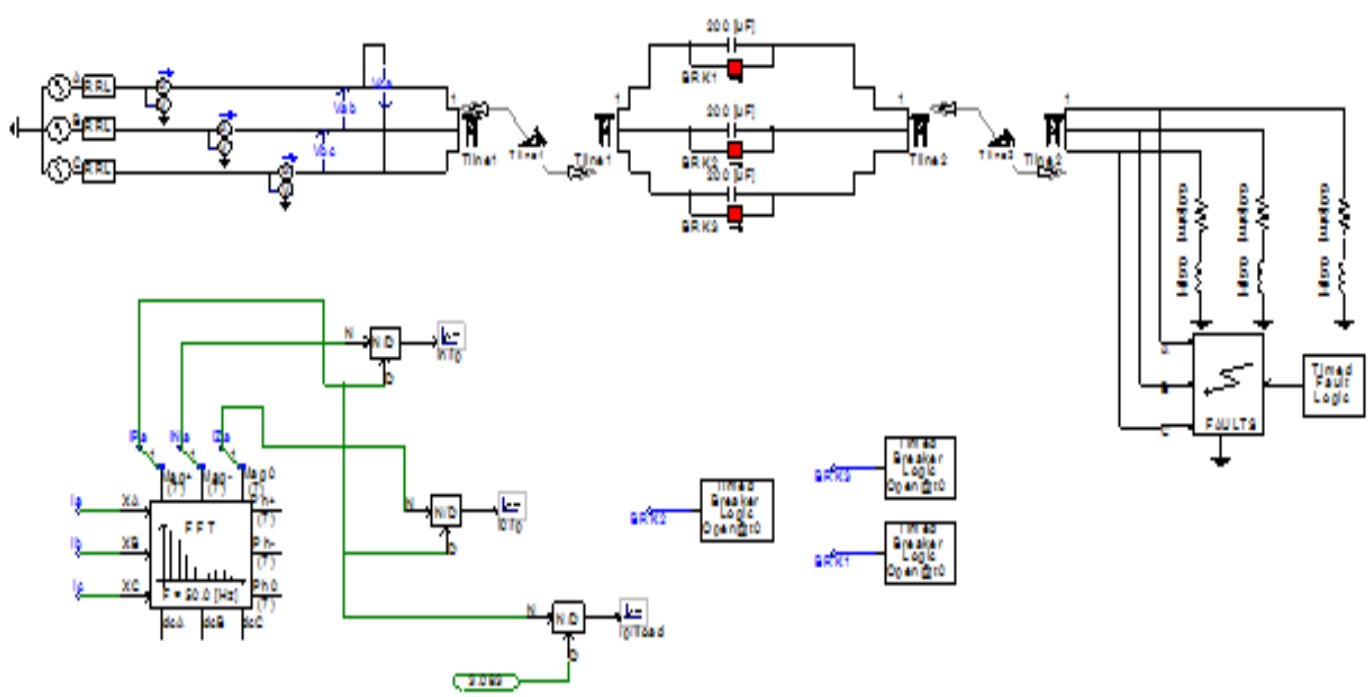

Fig. 1: Simulation model of line with series compensation capacitor at mid point 
Development of ANN Based Relay Algorithm for Protection of Series Compensated Transmission...

\section{1: Modelling of uncompensated transmission line}

The compensating capacitor was bypassed by closing the circuit breaker across it. Faults were created at remote end and middle of the line. The fault resistance was set to $0.1 \mathrm{ohm}$. A source is located at one end of the transmission line and a three phase load at the other end. A fault block has been used to simulate different types of fault. Eight values of inception angle were simulated: $0^{\circ}, 90^{\circ}, 180^{\circ}$ and $270^{\circ}$ for getting training data set and $45^{\circ}, 135^{\circ}, 225^{\circ}$ and $315^{\circ}$ for testing data set. Fault was created at $0.16 \mathrm{~s}$ and withdrawn at $0.26 \mathrm{~s}$.

Signals generated are shown here only for one type of fault at one location (remote end) to save space. Figure 2 shows the rms values of line voltages when line 'a' to ground fault is created at the remote end. It can be seen that during the fault, voltage $\mathrm{V}_{\mathrm{bc}}$ remains unchanged, but $\mathrm{V}_{\mathrm{ab}}$ increases and $\mathrm{V}_{\mathrm{ca}}$ decreases.

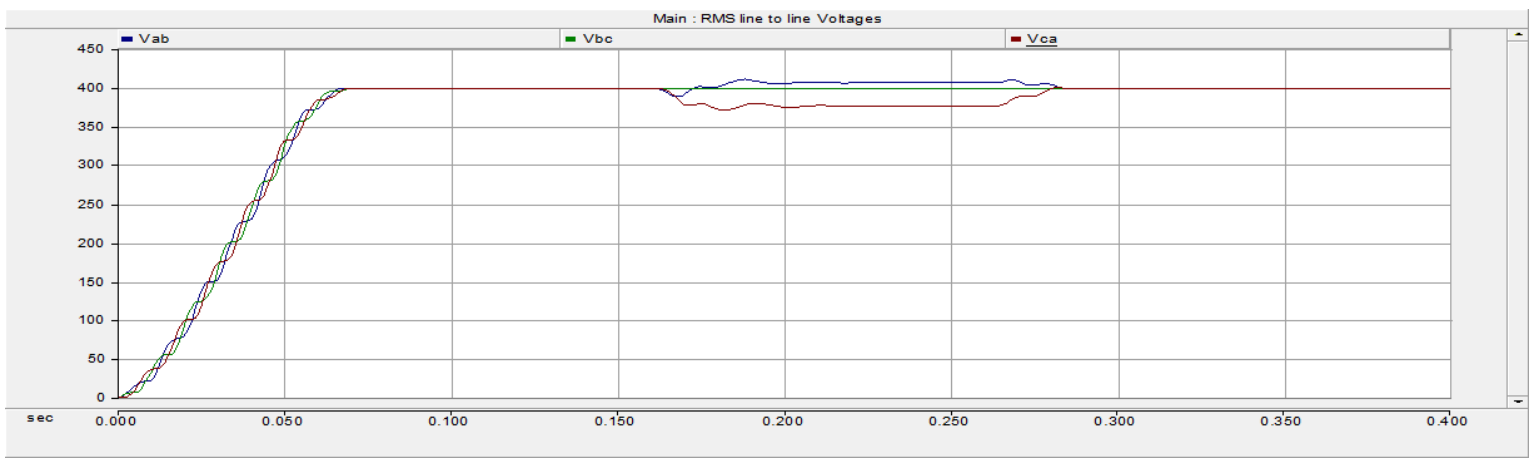

Fig. 2: Graph for RMS line voltages at remote end

Figure 3 shows the rms values of line currents. The current in the faulted phase increases to a value more than 4.5 times the prefault current.

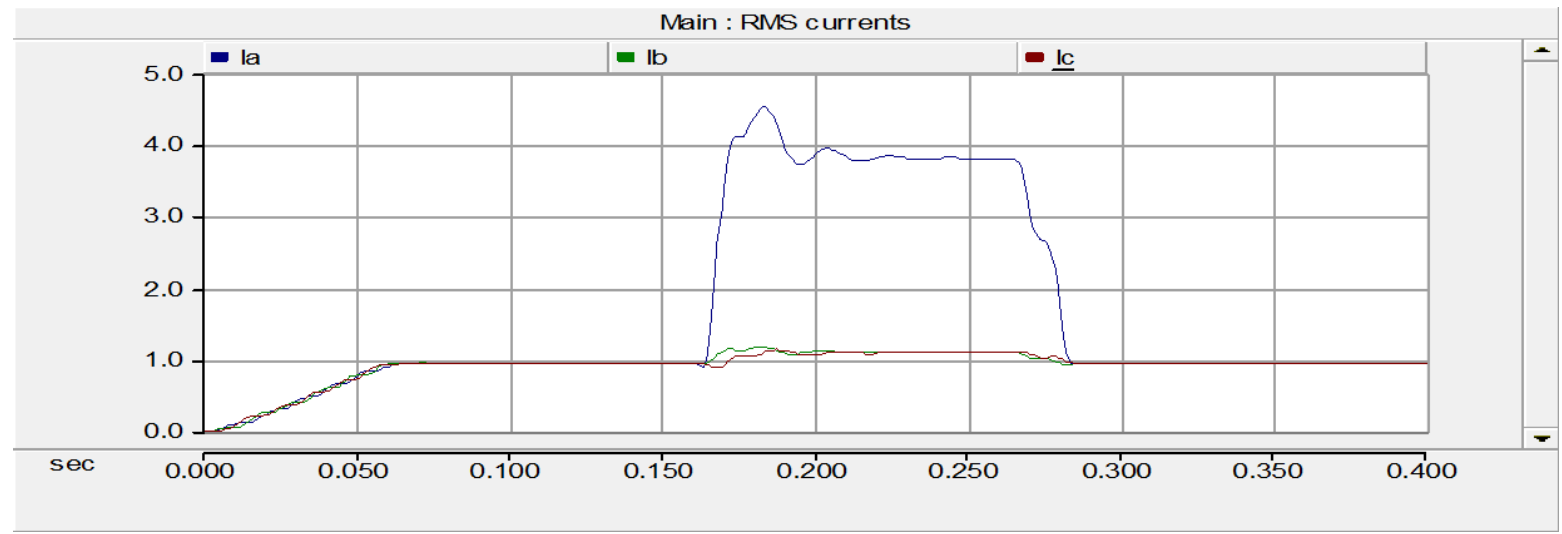

Fig. 3: Graph for RMS currents at remote end

Figure 4 shows the ratios of sequence currents. Here, all the three ratios of sequence currents $\left(I_{P} / I_{L} O a d, I_{0} / I_{P}\right.$, $\left.I_{n} / I_{P}\right)$ increase during the fault. The negative and zero sequence currents are zero before and after the fault,.

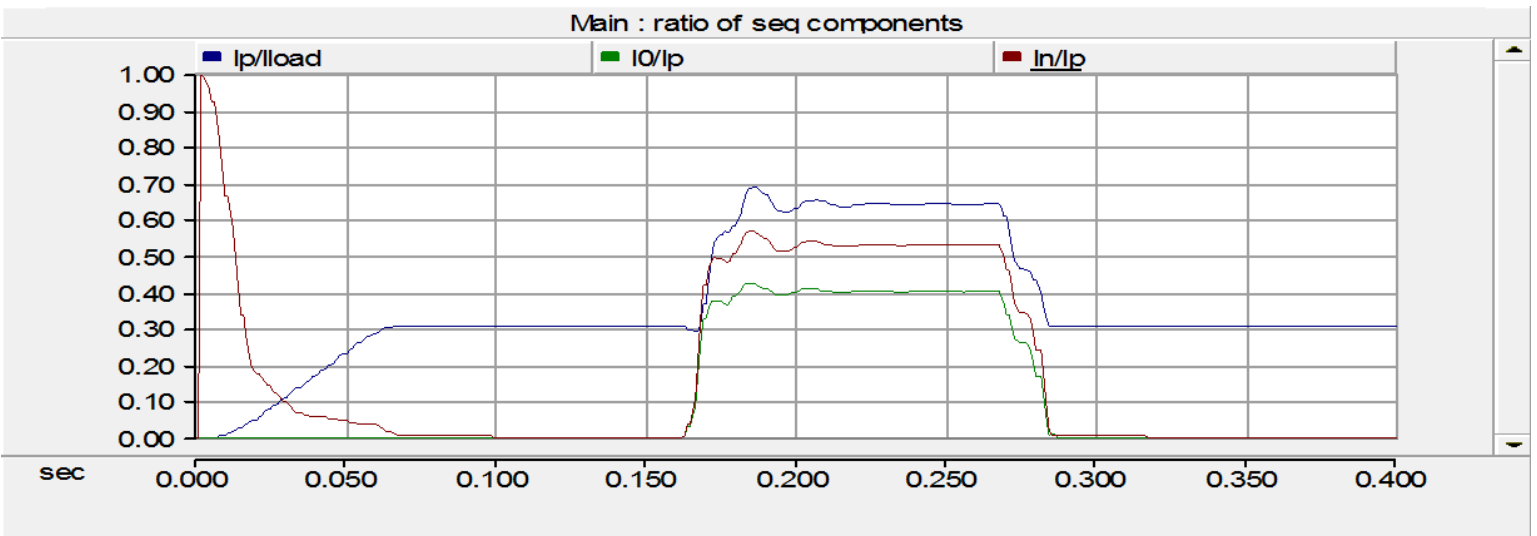

Fig. 4: Graph for ratio of sequence component currents at remote end 


\section{2: Modelling of series compensated transmission line}

The compensating capacitor was inserted here by opening the circuit breaker across it. With series capacitor located at the middle of the transmission line, faults were created at three different locations along the line: just before series capacitor, just after series capacitor and at the remote end of the line.

Figure 5 shows the rms values of line voltages when line ' $a$ ' to ground fault is created at the remote end. It can be seen that during the fault, voltage $V_{b c}$ remains unchanged, but $V_{a b}$ increases and $V_{c a}$ decreases. ]

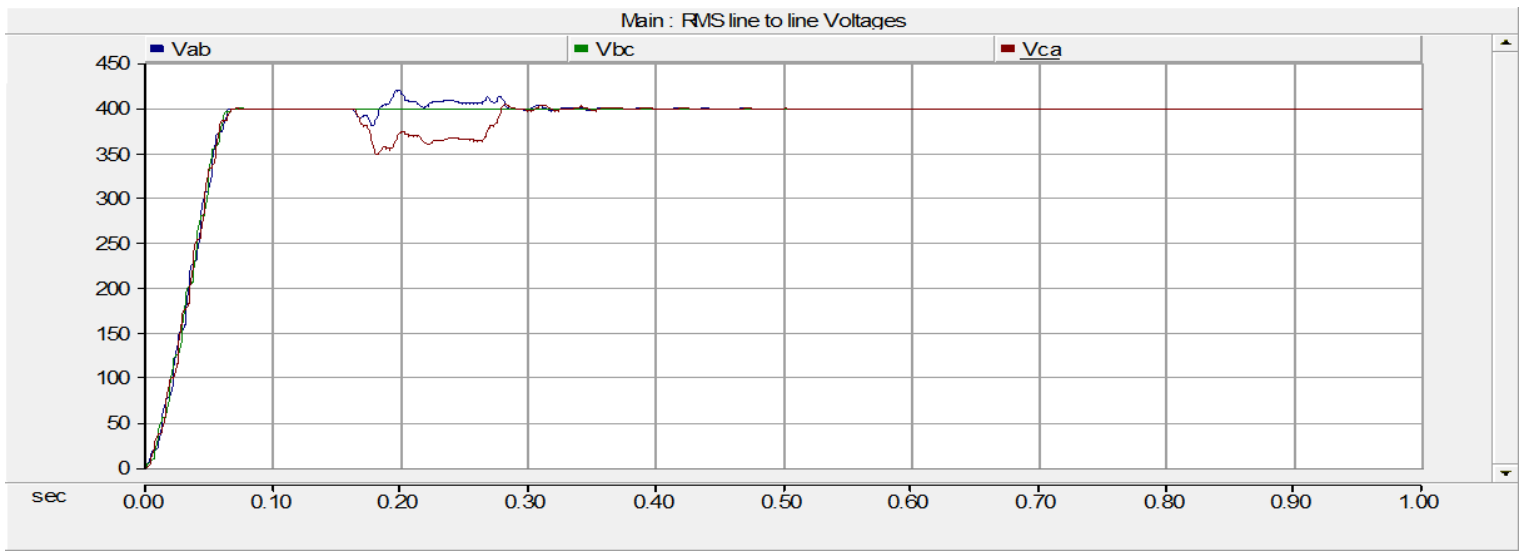

Fig. 5: Graph for RMS line voltages at remote end

Figure 6 shows the rms values of line currents in the series compensated line. The current in the faulted phase increases to a value more than 6.3 times the prefault current.

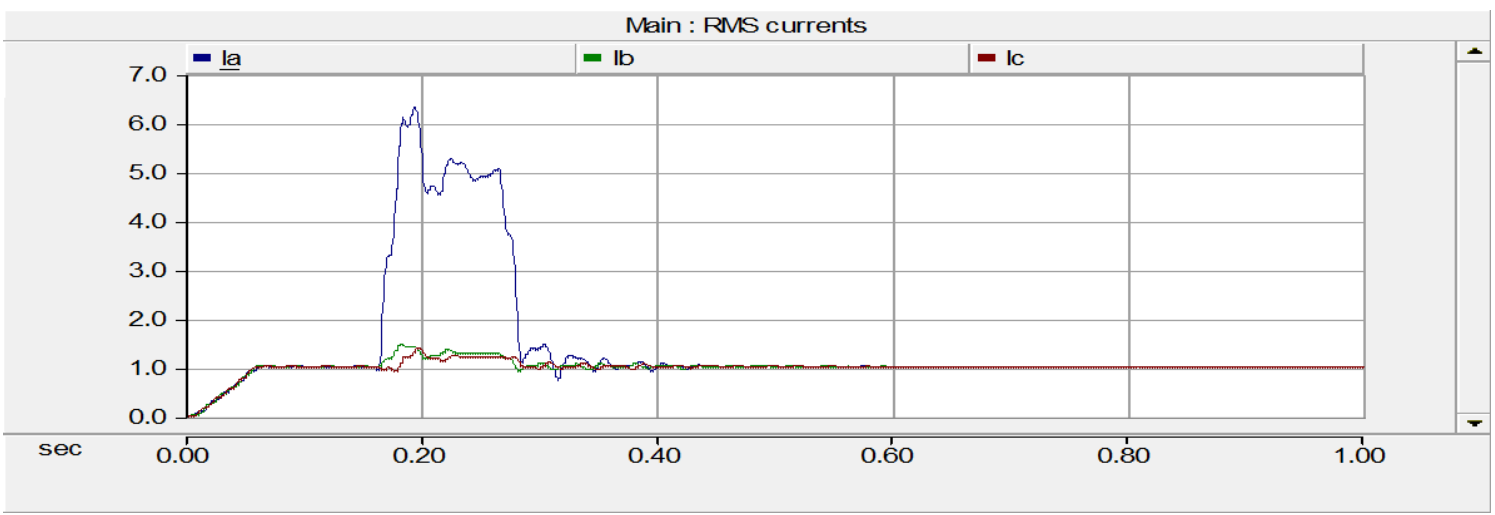

Fig. 6: Graph for RMS currents at remote end

Figure 7 shows the ratios of sequence currents at the source end. Here also, all the three ratios of sequence currents $\left(I_{P} / I_{L}\right.$ oad, $\left.I_{0} / I_{P}, I_{n} / I_{P}\right)$ increase at the instant of fault, while $I_{0} / I_{P}$ and $I_{n} / I_{P}$ are zero before and after the fault.

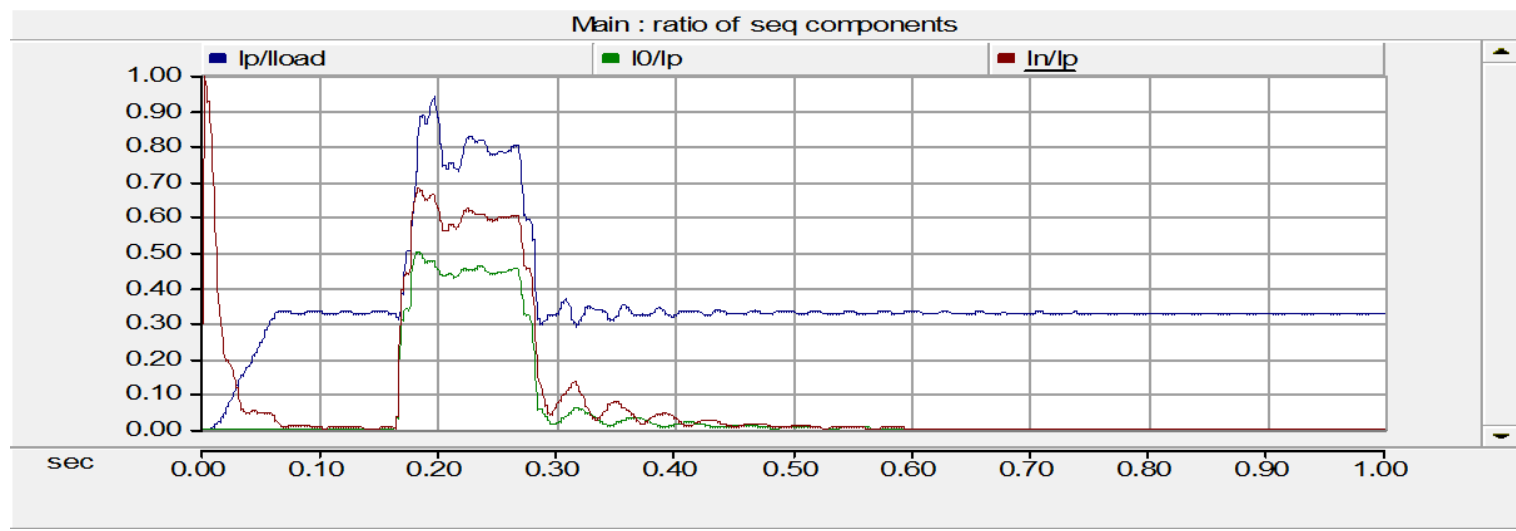

Fig. 7: Graph for ratio of sequence component currents at remote end 


\section{Ann Based Relay Algorithm}

In this section, details of the proposed neural-network based approach for the detection and classification of faults are given. A total of 8800 samples were generated from the simulated model for the purpose of training of the ANN and another 8800 samples were generated for testing.

\section{1: Proposed relay algorithm}

The relay algorithm shown in fig. 8 uses a back-propagation based neural network for the purpose of fault detection and fault classification. In this approach, the inputs to the ANN are taken from the data generated from the simulation done using PSCAD/EMTDC. The output ' 0 ' of ANN is true for no fault condition and one of the other outputs (1 to 10) is true depending on the type of the fault.

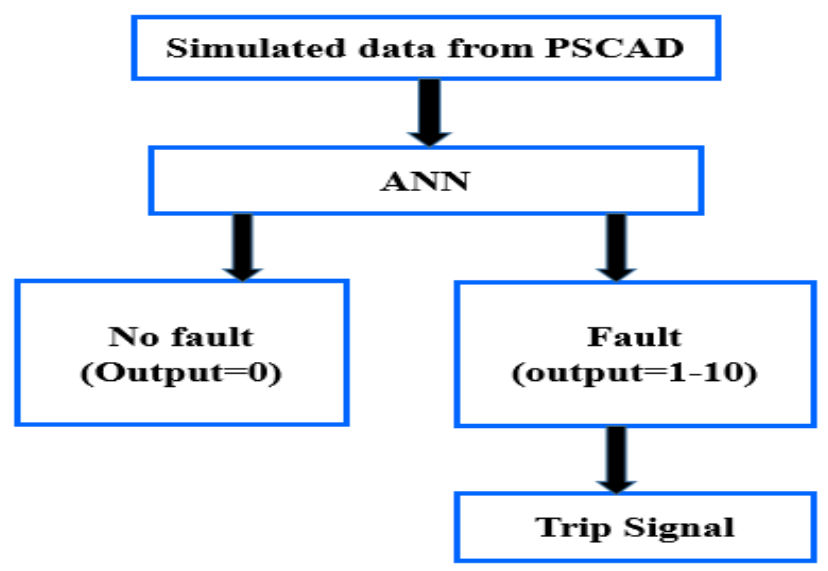

Fig. 8: Proposed relay algorithm

\section{2: ANN Configuration}

Configuration of the ANN used is shown in figure 9. It has 6 inputs, one hidden layer with 20 neurons and 11 outputs [5].

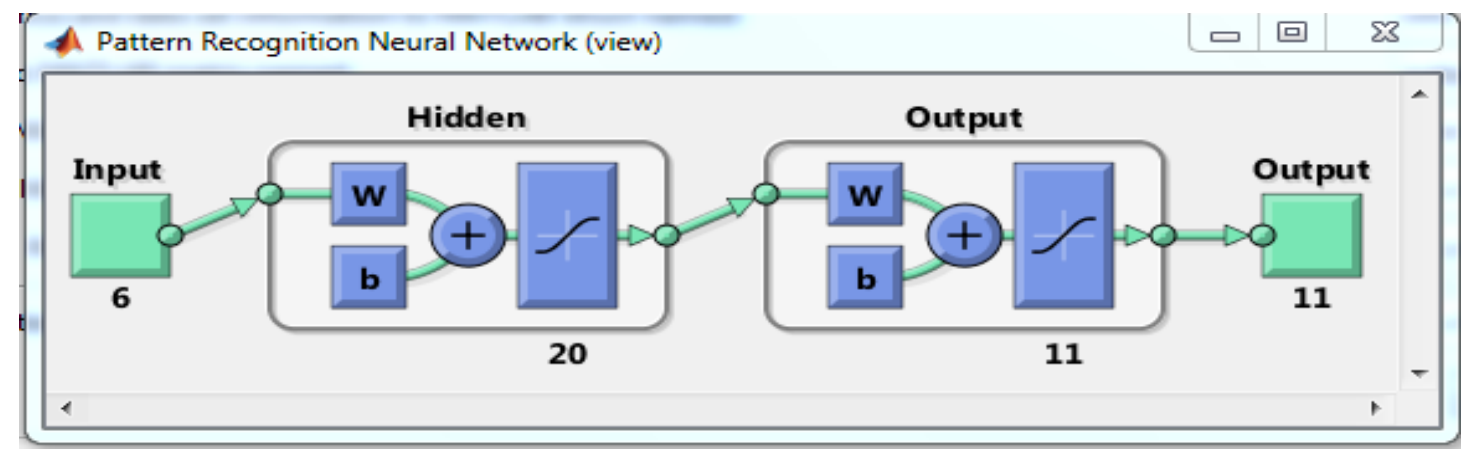

Fig. 9: Proposed ANN Scheme (6-20-11)

\section{3: Training}

The ANN was successfully trained to detect any type of fault. 40 samples each for eleven conditions of fault were generated. These 440 samples were generated for each of four different inception angles and hence 1760 samples were generated for one location of fault. Fault was created at two different locations on uncompensated line and three different locations on series compensated line and thus a total of 8800 samples were used for training ANN.

\subsection{1: Confusion matrix}

A confusion matrix is shown in figure 10. The diagonal cells indicate the number of cases that have been classified correctly by the neural network and the off diagonal elements indicate the number of cases that have been classified wrongly by the ANN. The last diagonal cell in each of the matrices indicates the overall percentage of cases that have been classified correctly. only $79.8 \%$

Figure 10 shows the confusion matrix for no delay. The overall accuracy of training can be seen to be 


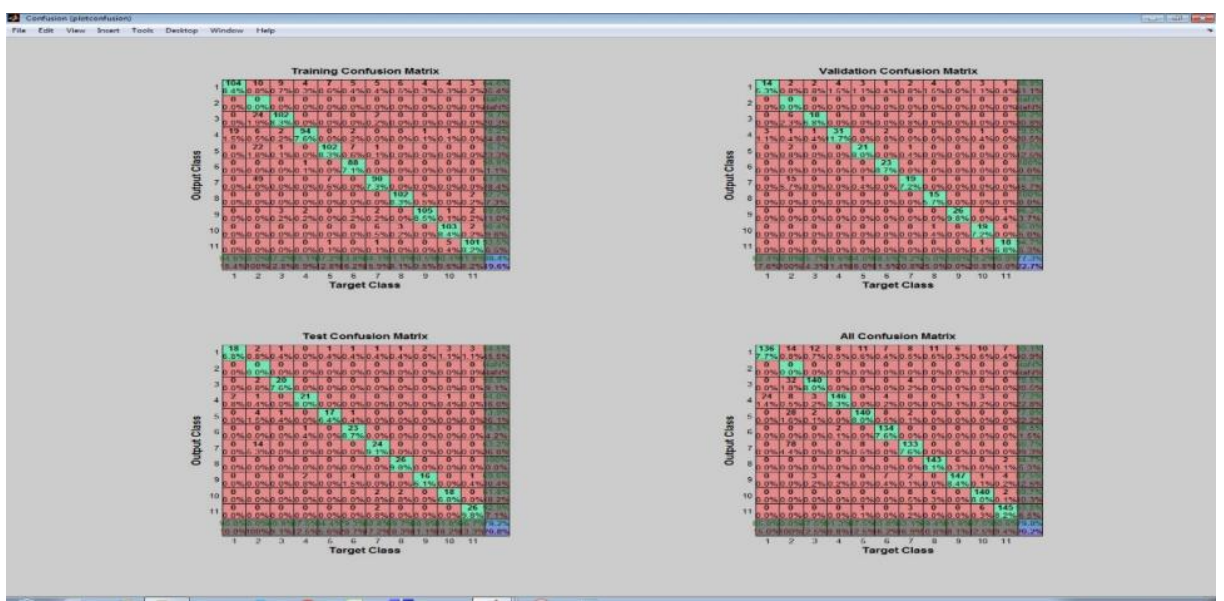

Fig. 10: Confusion matrix for training with no delay

ANN was then trained by introducing a delay of $5 \mathrm{~ms}, 10 \mathrm{~ms}, 11 \mathrm{~ms}$ and $12 \mathrm{~ms}$. At a delay of $12 \mathrm{~ms}$, an accuracy of $100 \%$ was achieved. Figure 11 shows the confusion matrix with a delay of $12 \mathrm{~ms}$.

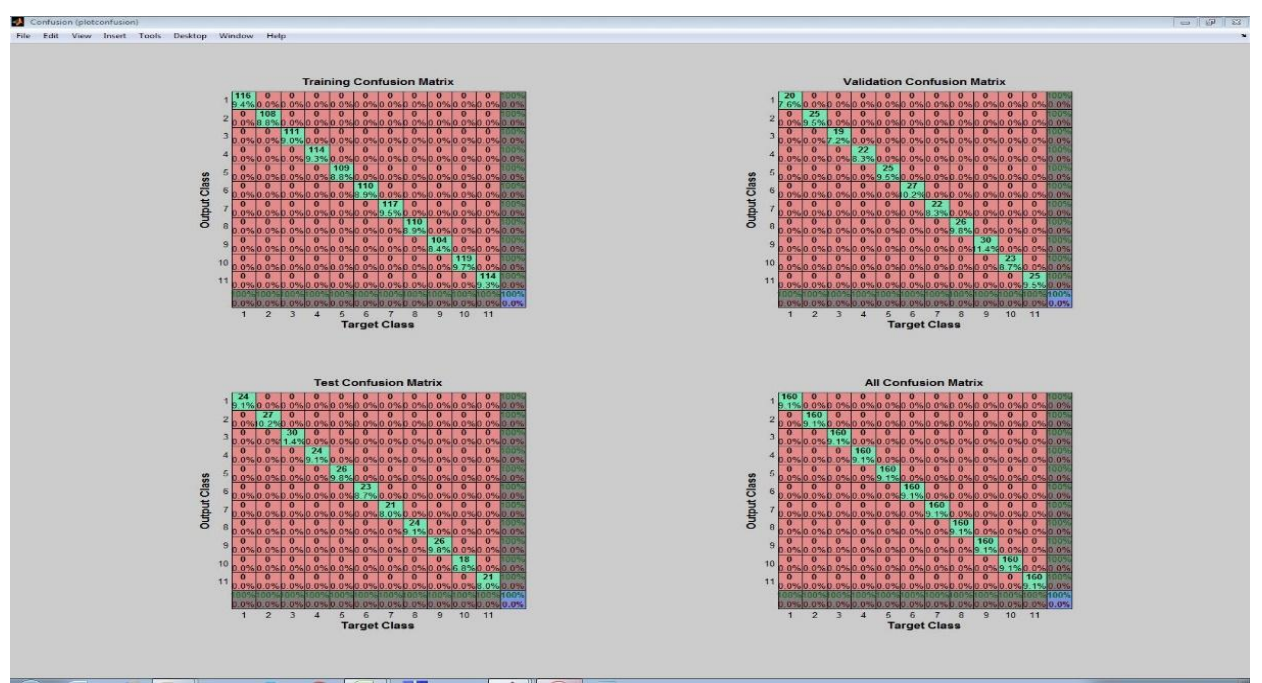

Fig. 11: Confusion matrix for training with 12 sample delay

\subsection{2: Mean square error (MSE) performance}

Figure 12 shows the training performance plot of the neural network. The overall MSE of the trained neural network is only 0.019309 by the end of the training process, which is very small.

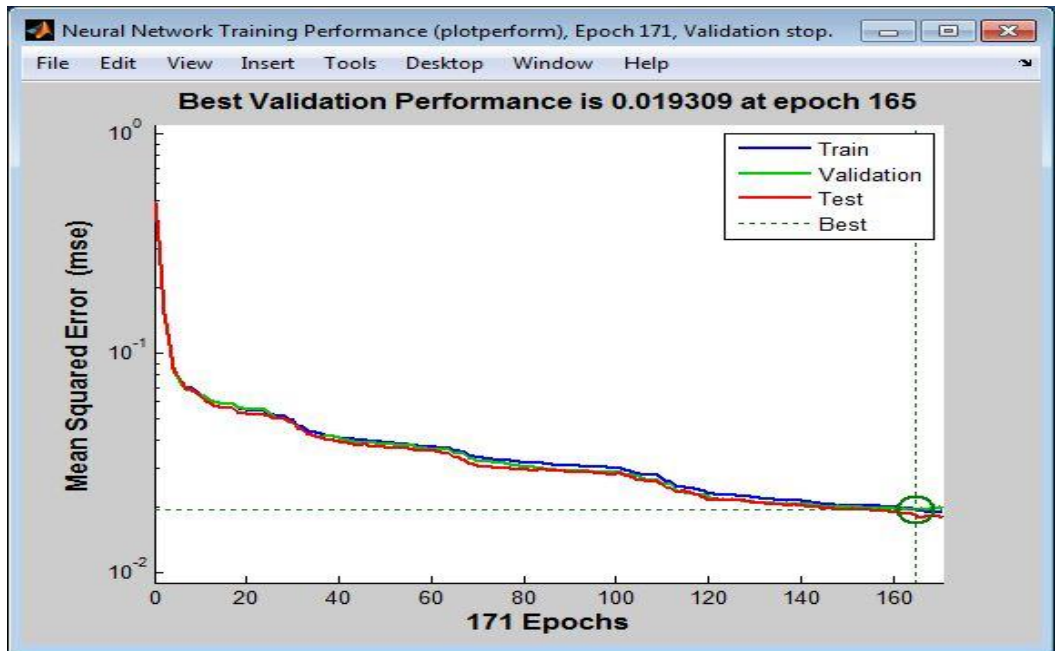

Fig. 12: Mean square error performance of the network 


\section{4: Testing}

Once the neural network had been trained, its performance was tested using a different set of 8800 samples as explained earlier.

\subsection{1: Confusion matrix}

Figure 13 shows the confusion matrix for the testing. An accuracy of $79 \%$ only was obtained with no delay in the samples. The ANN was tested by introducing delay $5 \mathrm{~ms}, 10 \mathrm{~ms}, 11 \mathrm{~ms}$ and $12 \mathrm{~ms}$. For a delay of $12 \mathrm{~ms}$, accuracy of $100 \%$ has been achieved as shown in figure 14 .

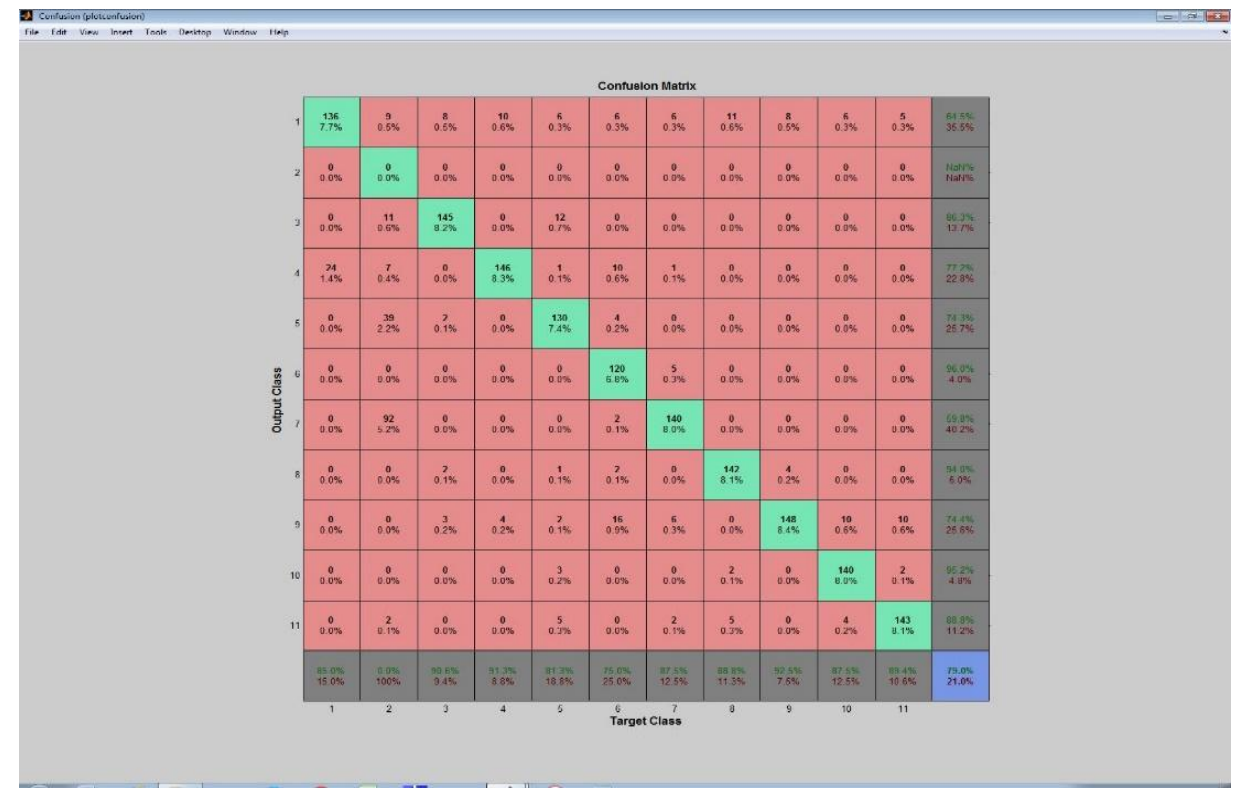

Fig. 13: Confusion matrix for testing with no delay

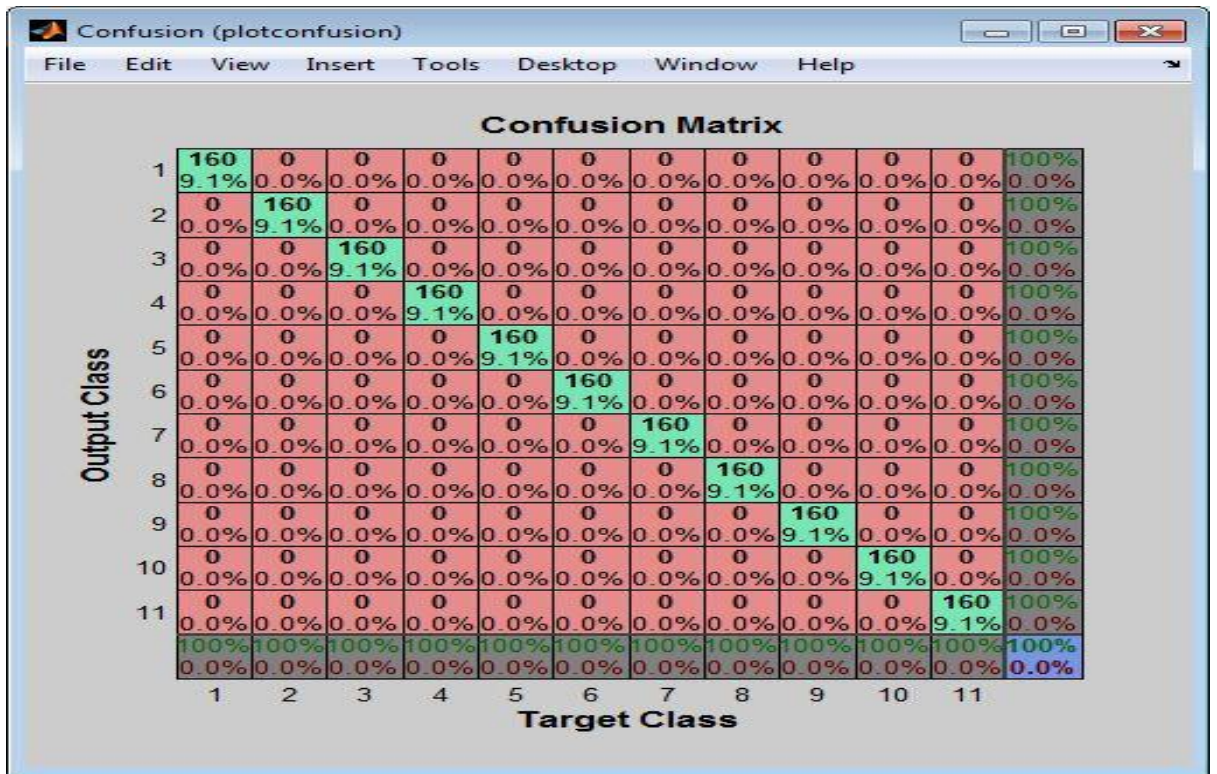

Fig. 14: Confusion matrix for testing with 12 sample delay

\subsection{2: Receiver operating characteristics $(\mathrm{ROC})$}

An ROC curve is the plot between the true positive rates (rate of positive classification) and the false positive rates (rate of incorrect classification) of the neural network classifier. Hence, an ideal ROC curve would show points only in the upper-left corner because that is an indication of 100 percent true positivity and 0 percent false positivity in the classification. It is to be noted that the ROC curves obtained here and plotted in Fig 15 are almost perfect since they all have the lines in the upper-left corner. 


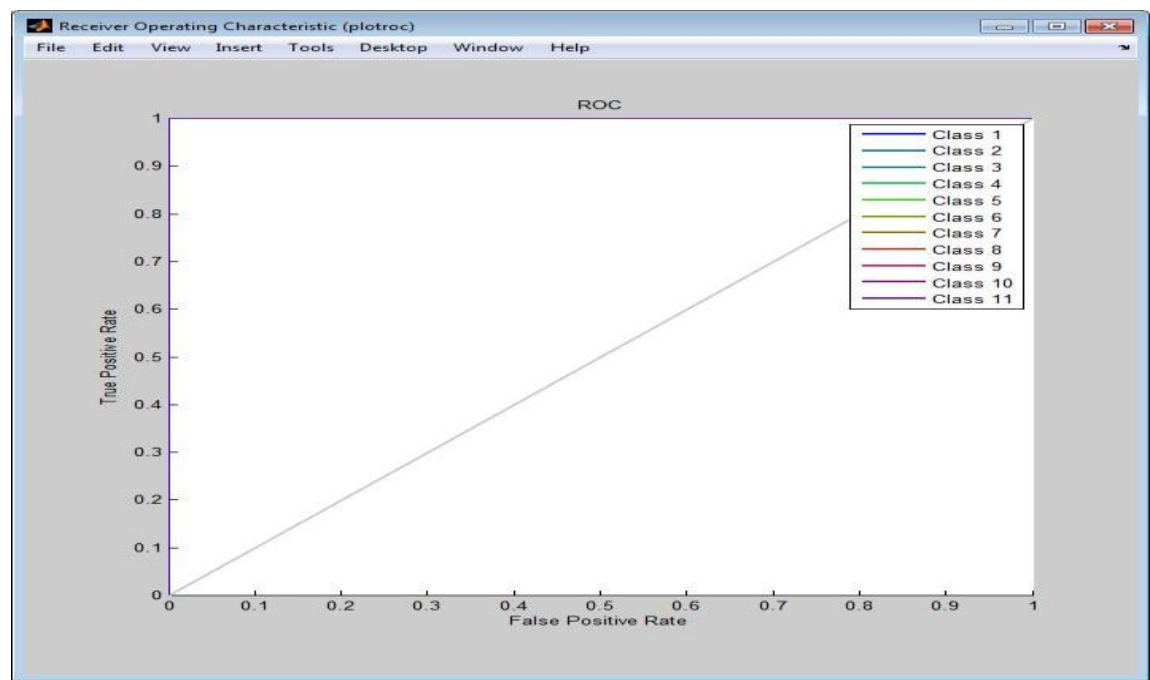

Fig. 15: Receiver operating characteristics of the network

\section{5: Accuracy versus delay characteristics}

Accuracy versus delay characteristics for training as well as testing of ANN are shown in figure 16 and table1. An accuracy of $100 \%$ is achieved for both training and testing at a delay of $12 \mathrm{~ms}$.

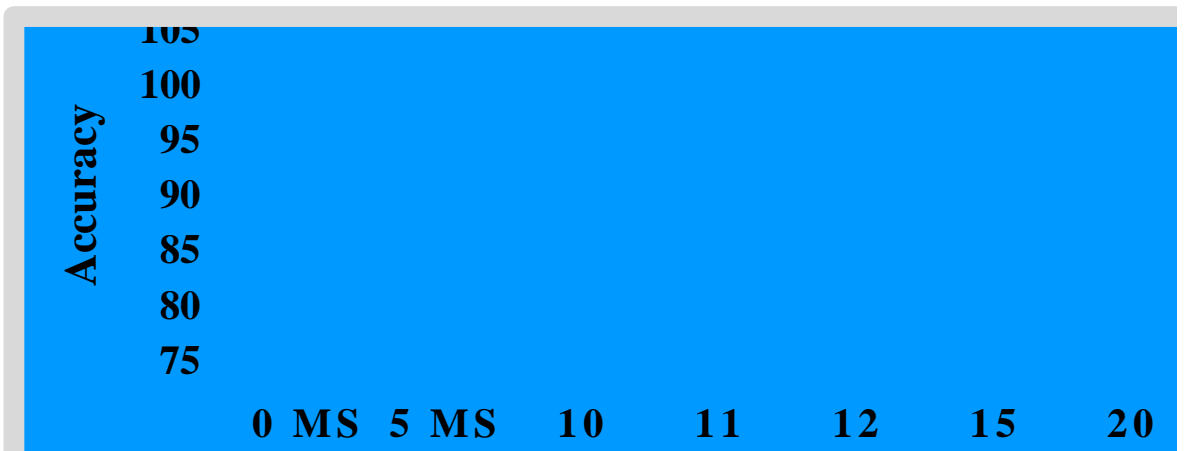

Fig. 16: Accuracy versus delay characteristics

Table 1: Accuracy versus delay data for training and testing phases

\begin{tabular}{|l|l|l|}
\hline Delay & Training & Testing \\
\hline $\mathbf{0} \mathrm{ms}$ & $\mathbf{7 9 . 8 \%}$ & $\mathbf{7 9 . 0 \%}$ \\
\hline $\mathbf{5} \mathrm{ms}$ & $\mathbf{9 8 . 8 \%}$ & $\mathbf{9 6 . 9 \%}$ \\
\hline $10 \mathrm{~ms}$ & $\mathbf{1 0 0 \%}$ & $\mathbf{9 9 . 5 \%}$ \\
\hline $11 \mathrm{~ms}$ & $\mathbf{1 0 0 \%}$ & $\mathbf{9 9 . 9 \%}$ \\
\hline $12 \mathrm{~ms}$ & $100 \%$ & $\mathbf{1 0 0 \%}$ \\
\hline $15 \mathrm{~ms}$ & $100 \%$ & $100 \%$ \\
\hline $20 \mathrm{~ms}$ & $100 \%$ & $100 \%$ \\
\hline
\end{tabular}

\section{Conclusion}

In this paper, successful development of an ANN based algorithm for the detection and classification of faults on series compensated transmission line has been reported. Different conditions of faults, namely single line to ground fault, line to line fault, double line to ground fault and triple line fault, along with normal operating condition, were simulated using PSCAD/EMTDC software. One data set generated from PSCAD/EMTDC for four values of fault inception angle was used as inputs to the ANN for training and another data set generated for different four values of fault inception angle were used for its testing. Finally, $100 \%$ accuracy has been achieved with relay operating time less than $3 / 4^{\text {th }}$ of a cycle.

The proposed algorithm is simple, reliable and accurate for all types of fault at all locations on the transmission line. It works with $100 \%$ accuracy with and without series capacitor. It is suitable for high resistance faults and is also not affected by variation of fault inception angle. 


\section{References}

[1]. Bogdan Kasztenny, "Distance Protection of Series Compensated Lines-Problems and Solutions", GE Power Management, Spokane, 2001 .

[2]. Clint T. Summers, "Distance Protection Aspects of Transmission Lines Equipped with Series Compensation Capacitors", Master of Science in Electrical Engineering Thesis, Virginia Plytechnic Institute and State University, September 29,1999 Blacksburg, VA.

[3]. Bhargav Vyas, Rudra Prakash Maheshwari, BiswarupDas, "Protection of series compensated transmission line: Issues and state of art", Electric Power Systems Research, vol. 107, 2014, pp.93-108.

[4]. Coury, D.V. and Jorge, D.C., "Artificial Neural Network Approach to Distance Protection of Transmission Lines", IEEE International Conference on Neural Networks, Electric Power Systems Research vol. 107, 2014, PP. $93-108$.

[5]. P. Kundur, "Power system Stability and Control", New York: Mc-Graw Hill, 1994.

[6]. J. B. Gupta, "Elements of Power Systems" S K Kataria and Sons publications, 1010 ISBN. 